\title{
중환자실에서의 재활치료
}

\author{
울산대학교 의과대학 서울아산병원 재활의학교실
}

김 원

\section{Rehabilitation in Intensive Care Unit}

\author{
Won Kim, M.D. \\ Department of Rehabilitation Medicine, Asan Medical Center, University of Ulsan College of Medicine, Seoul, Korea
}

\begin{abstract}
Correspondence to:
Won Kim, M.D.

Department of Rehabilitation

Medicine, Asan Medical Center,

University of Ulsan College of

Medicine, 88 Olympic-ro 43-gil,

Songpa- gu, Seoul 05505, Korea

Tel: +82-2-3010-3800

Fax: +82-2-3010-6964

E-mail: duoc179@gmail.com

ORCID:

http://orcid.org/0000-0002-9331-9795
\end{abstract}

In the past, critically ill patients in intensive care units have often been managed with bed rest and sedation. On the other hand, prolonged bed rest results in deconditioning and many survivors from the intensive care unit suffer from physical and mental sequelae. Therefore, rehabilitation in intensive care units has been started to prevent them. Recently, many positive results about the effectiveness and safety of rehabilitation in intensive care units were published. In this review, the evidence and the practical point of rehabilitation in intensive care units are discussed. (J Acute Care Surg 2018;8:2-6)

Key Words: Rehabilitation, Intensive care units, Early ambulation

Received September 27, 2017, Revised April 14, 2018, Accepted April 16, 2018

Copyright (C) 2018 by Korean Society of Acute Care Surgery

(c) This is an Open Access article distributed under the terms of the Creative Commons Attribution Non-Commercial License (http://creativecommons.org/licenses/by-nc/4.0) which permits unrestricted non-commercial use, distribution, and reproduction in any medium, provided the original work is properly cited.

ISSN 2288-5862(Print), ISSN 2288-9582(Online)

https://doi.org/10.17479/jacs.2018.8.1.2

서론

이전에는 중환자를 치료함에 있어서 진정을 시키고 침상안정 을 하여 내/외과적 문제를 치료하는 것에만 집중하였다. 이에 중환자실에서의 재활치료는 간단한 수동적인 관절가동범위 운동 을 하는 정도에만 국한되었다. 하지만 오랜 기간의 부동은 신체 쇠약을 유발하고, 심부정맥혈전증과 같은 합병증을 초래하게 된 다. 또한 중환자실에서 내/외과적 문제가 해결된 이후에 장기간 의 시간이 지나도 근력 및 운동능력이 정상수준으로 회복되지 않는 경우가 많음을 알게 되었다. 이에 2000년대에 들어서 중환자 실 내에서도 보행을 포함한 적극적인 재활치료가 시도되었고, 안전성과 효과에 대한 근거가 축적되었다. 본 글에서는 중환자
재활치료의 전반에 대해서 살펴보고자 한다.

\section{본론}

\section{집중치료 후 증후군}

집주치료실에서 치료 후에 나타나는 신체적인 장애, 정신건강 의 문제, 인지 장애를 통틀어서 집중치료 후 증후군(post intensive care syndrome, PICS)이라고 한다[1]. 신체적인 장애는 가장 두드 러지고 예상할 수 있는 변화이다. 장기간의 침상안정은 근력 약화 를 유발하고, 특히 이는 하지 근육에서 더 심하게 나타난다. 무릎 신전근의 경우에 1 주간의 침상안정은 $15 \%, 5$ 주간의 침상안정은 $25 \%$ 의 근력 감소를 야기한다[2]. 이러한 변화는 호흡근에도 나타 
나는데, 인공호흡기를 2 3일 적용하는 것만으로도 횡경막근육 의 위축을 유발한다[3]. 침상안정에 의한 단순한 근위축 외에도 중증질환신경근병증(critical illness neuromyopathy)은 신경근육 계에 병적인 변화를 유발한다[4]. 이러한 신체적 변화는 기저질환 이 호전된 이후에도 충분히 회복되지 않을 수 있다. 급성호흡부전 을 겪은 환자에서의 연구를 보면 호흡부전으로 치료를 받은 이후 5년이 지난 시점에서 폐기능은 거의 정상으로 회복됨에도 불구하 고 6분 보행거리가 정상 대조군의 $76 \%$ 에 지나지 않았다[5]. 집중 치료실에서의 치료는 신체기능의 장애뿐만 아니라 인지기능의 저하도 유발하게 되는데, 패혈증 이후에 인지기능의 장애가 3.34 배 증가하는 것으로 보고되었다. 또한 집중치료실에서의 치료 후에는 정신건강에도 문제가 발생할 수 있는데 불안증, 외상 후 스트레스장애, 우울증 등이 대표적이다[1].

\section{중환자 재활치료의 안전성}

$\mathrm{PICS}$ 를 극복하고, 침상안정으로 인한 합병증을 줄이고, 환자의 회복을 빠르게 하기 위해서 중환자실에서의 재활치료가 시도되 었다. 시도 초기에 중환자에게 재활치료를 시행하는 것의 실행가 능성과 안전성에 대해 많은 연구가 시행되었다. 지금까지의 연구 결과를 보면 중환자실에서의 재활치료는 인공호흡기를 하는 경 우뿐만 아니라 고령의 환자, continuous renal replacement therapy (CRRT)나 extracorporeal membrane oxygenation (ECMO)을 적 용하는 환자에서도 안전하게 적용이 가능하다[6]. 재활치료 시의 산소포화도의 저하, 심박수나 혈압의 변화, 각종 수액선이나 배액 관의 탈관, 낙상 등이 발생할 수 있지만, 휴식이나 간단한 조치로 회복되며, 환자의 예후나 치료에 영향을 줄만한 심각한 이상반응 은 거의 발생하지 않는다[7,8]. 하지만 모두 일률적인 기준을 가지 고 재활치료를 시행하는 것은 적절치 않으며 각 중환자실의 특성 에 따라서 적절한 시행 및 중단 기준을 정하여 이에 따라 시행해야 한다. 적절한 수준의 활력징후 및 검사결과의 안정과 협조가 가능 한 의식수준, 체중지지 및 관절 운동이 가능한 근골격계의 안정성 이 요구된다[?].

\section{중환자 재활치료의 효과}

메타분석에 따르면 중환자 재활치료는 신체기능, 삶의 질, 사지 및 호흡근 근력을 향상시키고, 인공호흡기 없이 지내는 기간을 늘리고, 병원 및 중환자실 재원기간을 단축시킨다[10]. 특히 중환 자의 예후를 호전시키기 위한 영양, 진정요법, 조기 기관절개 등의 다양한 시도들을 분석했을 때에 운동기능을 향상시킬 수 있는 것은 재활치료가 유일한 것으로 보고되었다[11]. 하지만 재
원기간 중 사망률을 줄이지는 못하는데[10,12], 이는 재원기간 중의 사망에 영향을 미치는 요인이 매우 다양하기 때문에 재활치 료만으로는 큰 영향을 주지는 못하는 것으로 생각된다. 하지만 일반인구집단에서도 신체기능의 향상은 장기 생존율을 향상시키 기 때문에 중환자 재활치료를 통해서 신체기능의 저하를 막고, 스스로 활동량을 유지하고 건강관리가 가능하도록 해주는 것은 장기 생존율을 향상시킬 것으로 생각된다. 한 연구에서는 패혈증 으로 중환자실 치료를 받은 환자에서 퇴원 후에 지속적으로 재활 치료를 하는 경우에 $1,3,5,10$ 년 생존율이 향상되며, 특히 양-반응 상관관계가 있었다[13]. 이를 종합해 볼 때 중환자실 입실 시와 퇴실 이후에서의 지속적인 재활치료는 장기 생존율을 향상시킬 것으로 생각된다.

이러한 재활치료의 효과는 환자군의 특성에 따라 다를 수 있을 것으로 보인다. 내과계 환자의 경우에 만성질환으로 인해 기저 신체기능의 저하가 심하여 재활치료의 효과가 적을 수 있는 데 반해, 외과계 환자의 경우에 기저 신체기능이 대체로 양호하여 중환자실에서 적절한 치료 및 재활로 양호한 신체기능의 회복이 가능할 것으로 기대된다. 실제 외과계 중환자를 대상으로 한 연구 에서 내과계 환자에 대한 기존 보고에 비해서 더 우수한 치료효과 가 보고된 바가 있으나[14,15], 연구 조건이 각기 다르기 때문에 단순 비교하여 결론을 내리기는 어렵다.

외상 환자에서의 중환자 재활치료의 효과에 대해서 특화되어 연구된 바는 거의 없다. 둔탁한 내부장기 손상(blunt solid organ injuries)을 입고 비수술적 치료를 받는 경우에 빨리 보행을 시켜도 손상부위의 파열이 증가하지는 않는 것으로 보고되었으며[16], 외상 및 화상 중환자실에서 조기 거동이 안전하며, 호흡기계 및 혈관계 합병증이 줄어들었다는 보고 정도가 있다[17]. 외상 환자 에서 손상부위에 따라서 적극적인 재활치료의 가능 여부에 대해 서 명확한 근거는 없으나 복부장기 손상의 경우에 많은 경우에 적극적인 재활치료가 가능한 것으로 생각된다[18]. 하지만 척추나 하지 골절이 있는 경우에는 해당부위에 안정성(stability)이 확보된 이후에 체중 부하를 고려할 수 있으며, 그 정도와 시점에 대해서 정형외과, 신경외과 전문의와의 상의가 필요하다. 또한 중추신경 계 손상이 있는 경우에는 의식저하로 인해서 적극적인 재활치료 가 불가능하거나 합병증이나 처치 상태를 고려해서 결정해야 한다. 이렇게 능동적인 치료가 어려운 경우에는 신경근 전기자극 (neuromuscular electrical stimulation)이 근육량을 유지하는 데 도움이 될 수 있다. 


\section{중환자 재활치료의 실제}

중환자 재활치료는 다양한 의료진의 협업이 매우 중요하다. 중환자실 담당의사, 간호사, 재활의학과 의사, 물리치료사가 유기 적으로 협조가 되어야 재활프로그램이 효율적으로 운영이 될 수 있다. 초기에 재활치료를 처음 도입할 때에는 각 의료진이 모여서 대상자에 대한 논의와 안전체크리스트와 치료 중단의 기준, 재활치료 프로그램, 효과 및 안전성 평가지표를 마련해야 한다(Table 1). 특히 각 중환자실의 특성에 따라서 치료 대상자와 안전체크리스트의 항목은 달라질 수 있어서 기존에 발표된 기준 들에 더하여 담당 의료진의 의견이 적절히 융화되어야 한다.

재활치료의 프로그램은 중환자라고 해서 특별한 것은 아니다. 여러 발표된 재활프로그램들을 어느 정도의 공통점이 존재한다. 일단 의식이 없는 상태에서는 수동적 관절 운동을 하고, 협조가 가능해지면 침상에서의 능동적인 관절 운동을 시행한다. 어느 정도 몸통의 균형을 잡을 수 있게 되면 침상 끝에 걸터앉아서 균형잡기와 상하지 근력 운동을 시행하고, 하지 근력의 회복 정도 에 따라서 서고, 걷는 훈련을 진행한다. 실제 중환자실 환자의 경우에는 인공호흡기와 각종 보조장치들로 인해서 보행훈련을

Table 1. Examples of stop criteria during intensive care unit rehabilitation

Dyspnea (respiration rate $>35$ beat per minute, use of accessory muscle)

Cyanosis

Desaturation (blood oxygen saturation $<90 \%$ )

Dizziness

Tachycardia (increase 30 beat per minute more than baseline)

Patient intolerance (ex. sweating, trembling $\cdots$ )

Patient refuse

Decision of participants (physical therapist, Rehabilitation nurse)

Medical device removal (unable to rehabilitation)

Fall down (unable to rehabilitation)

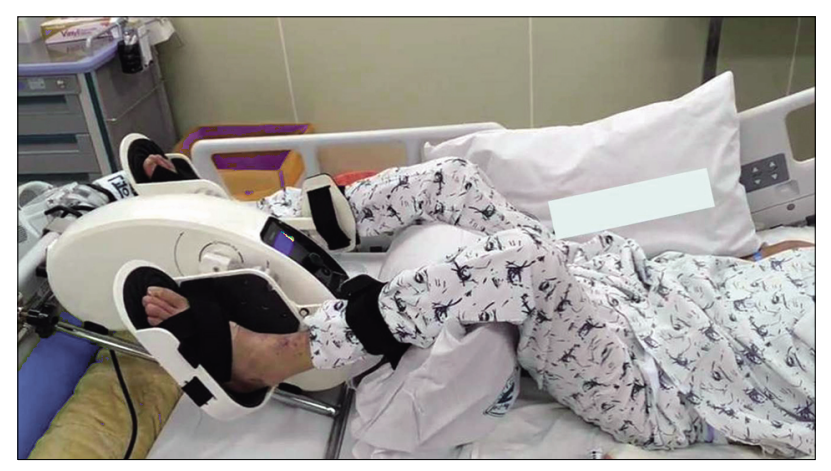

Fig. 1. Bedside ergometer.
하기 어려운 경우가 많은데, 무릎을 약간 구부렸다 폈다를 반복하 는 웅크림(squatting) 운동은 운동강도도 상당하고 제자리에서 할 수 있어서 좋은 대안이 된다. 능동적인 운동을 하기 어려운 경우나, 능동적인 운동의 보조적인 수단으로 신경근 전기자극을 적용할 수도 있다[19]. 신경근 전기자극은 처음 적용할 때에 능동 적 운동보다 근손상이 더 쉽게 일어날 수 있기 때문에, 낮은 강도 부터 시작해서 점차적으로 강도를 높여야 한다. 이에 더하여 호흡 근 운동을 같이 시행할 수도 있는데, 호흡근 저항훈련을 통해서 호흡근 강화를 하는 것이 중환자실에서도 가능하고, 인공호흡기 적용 기간을 줄일 수 있다[20].

실제 재활치료를 적용하기 위해서는 프로그램의 내용뿐만 아 니라 시스템의 운용이 매우 중요하다. 국내에서는 수가의 제한으 로 인하여 충분한 시간을 치료하기 어렵기 때문에 주어진 시간 안에서도 낭비되는 시간이 없이 효율적으로 치료가 진행되게 해야 한다. 하지만 각 직역은 자신이 맡은 일들만 신경을 쓰게 되기 때문에 효율적인 재활치료는 실제로 시행하기가 쉽지 않다. 재활치료를 하러 치료사가 방문하였으나 환자는 검사를 가거나, 상태악화로 치료를 하지 못하게 되는 경우가 흔히 발생하게 된다. 이를 극복하기 위해서는 중환자 재활치료를 전담하는 코디네이 터를 두는 것이 도움이 된다. 코디네이터가 환자 스크리닝, 치료 전 환자 준비, 치료 스케줄을 조정하는 것은 전체적인 시스템이 잘 운영되도록 해 준다. 또한 간호사가 재활치료 시 활력징후 및 환자 상태를 모니터링을 해주는 것이 필요하다.

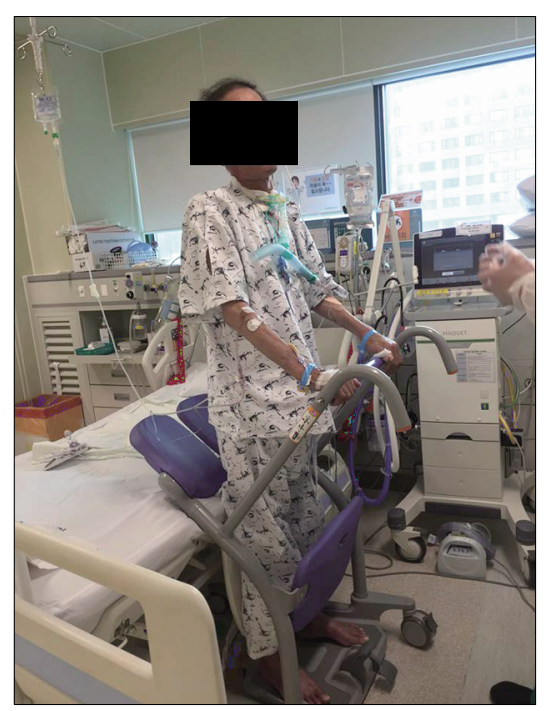

Fig. 2. Standing training with $\operatorname{Sara}^{\circledR}$ Stedy. 


\section{재활치료 장비}

기본적으로 재활치료는 물리치료사가 환자에게 1 대 1 로 붙어 서 시행하고, 가능하면 환자가 체중지지를 하고 능동적인 근 수축 을 하도록 유도하는 것이 가장 효과적이다. 즉 중환자실에서 재활 치료를 시행하는 데는 기본적으로 특별한 장비가 구비되어 있지 않아도 무방하다. 하지만 몇 가지 재활치료 장비가 구비되면 더 안전하고 효과적으로 재활치료를 시행 할 수 있다. 신경근 전기자 극은 전기자극을 통해서 근육이 수축되도록 하여 근육 운동을 시키는 장치이다. 이는 능동적인 근력 운동을 하는 것에 비해서는 효과가 부족하지만 의식이 없는 환자나, 추가적인 재활치료 방법 으로, 또는 재활치료를 할 수 있는 인력이 부족한 경우에 보조적인 방법으로 시행할 수 있다. 처음 신경근 전기자극을 시행할 때에는 근육손상이 일어날 수 있기 때문에 처음에는 약한 강도로 시행해 서 점차 자극강도를 높여야 한다. 침상에서 할 수 있는 어고미터 (bedside ergometer)는 유산소 운동을 할 수 있고 설치만 해두면 치료사 없이도 20 30분 정도 능동적인 운동이 가능하다는 장점 이 있다(Fig. 1). 이전에는 1,000만원 이상 가격이 나가고 크기가 큰 장비만 있었으나 최근에는 100 만원 정도의 간단한 구조의 장비도 구매가 가능하다. 다만 누워서 자전거를 타는 형태이기 때문에 발판이 다른 자전거형 운동기구만큼 큰 힘을 받기 어렵고 크기의 제한도 있어서 운동강도를 높이는 데 제한이 있다. 그 외에도 Sara Stedy (Sara ${ }^{\circledR}$ Stedy; Arjo, Malmö, Sweden)와 같이 자세를 보조해주는 장치를 사용하면 치료사의 노동강도를 낮춰 주면서 안전하게 기립 및 하지 근력 운동을 시행할 수 있다(Fig. 2).

\section{결론}

중환자 재활치료는 최근 10 년간 빠르게 확산되고 있고, 그 안전성과 효과에 대한 근거가 축적되어왔다. 중환자 재활치료는 특별한 첨단 기술이 필요한 것이 아니고 구성원들이 환자를 위해 이를 시행하고자 하는 의지가 가장 중요하다. 실제 시행함에 있어 서는 프로그램의 준비단계에서부터 다학제 간의 유기적인 협조 와 효율적인 운영 프로세스 마련이 필수적이다. 낮은 수가구조와 인력부족은 국내에서 중환자 재활치료의 활성화를 막고 있다. 하지만 장기적인 환자의 예후를 생각할 때 중환자 치료에 재활은 필수적으로 포함되어야 할 것이다.

\section{Conflicts of Interest}

No potential conflict of interest relevant to this article was reported.

\section{References}

1. Needham DM, Davidson J, Cohen H, Hopkins RO, Weinert $\mathrm{C}$, Wunsch $\mathrm{H}$, et al. Improving long-term outcomes after discharge from intensive care unit: report from a stakeholders' conference. Crit Care Med 2012;40:502-9.

2. LeBlanc AD, Schneider VS, Evans HJ, Pientok C, Rowe R, Spector E. Regional changes in muscle mass following 17 weeks of bed rest. J Appl Physiol (1985) 1992;73:2172-8.

3. Levine S, Nguyen T, Taylor N, Friscia ME, Budak MT, Rothenberg P, et al. Rapid disuse atrophy of diaphragm fibers in mechanically ventilated humans. N Engl J Med 2008; 358:1327-35.

4. Stevens RD, Dowdy DW, Michaels RK, Mendez-Tellez PA, Pronovost PJ, Needham DM. Neuromuscular dysfunction acquired in critical illness: a systematic review. Intensive Care Med 2007;33:1876-91.

5. Herridge MS, Tansey CM, Matté A, Tomlinson G, Diaz-Granados N, Cooper A, et al. Functional disability 5 years after acute respiratory distress syndrome. N Engl J Med 2011;364:1293-304.

6. Abrams D, Javidfar J, Farrand E, Mongero LB, Agerstrand CL, Ryan P, et al. Early mobilization of patients receiving extracorporeal membrane oxygenation: a retrospective cohort study. Crit Care 2014;18:R38.

7. Li Z, Peng X, Zhu B, Zhang Y, Xi X. Active mobilization for mechanically ventilated patients: a systematic review. Arch Phys Med Rehabil 2013;94:551-61.

8. Nydahl P, Sricharoenchai T, Chandra S, Kundt FS, Huang M, Fischill M, et al. Safety of patient mobilization and rehabilitation in the intensive care unit. Systematic review with meta-analysis. Ann Am Thorac Soc 2017;14:766-77.

9. Hanekom S, Gosselink R, Dean E, van Aswegen H, Roos R, Ambrosino N, et al. The development of a clinical management algorithm for early physical activity and mobilization of critically ill patients: synthesis of evidence and expert opinion and its translation into practice. Clin Rehabil 2011;25:771-87.

10. Kayambu G, Boots R, Paratz J. Physical therapy for the critically ill in the ICU: a systematic review and meta-analysis. Crit Care Med 2013;41:1543-54.

11. Calvo-Ayala E, Khan BA, Farber MO, Ely EW, Boustani MA. Interventions to improve the physical function of ICU survivors: a systematic review. Chest 2013;144:1469-80.

12. Tipping CJ, Harrold M, Holland A, Romero L, Nisbet T, Hodgson CL. The effects of active mobilisation and rehabilitation in ICU on mortality and function: a systematic review. Intensive Care Med 2017;43:171-83.

13. Chao P, Shih CJ, Lee YJ, et al. Association of postdischarge rehabilitation with mortality in intensive care unit survivors of sepsis. Am J Respir Crit Care Med 2014;190:1003-11.

14. Schweickert WD, Pohlman MC, Pohlman AS, Nigos C, Pawlik AJ, Esbrook CL, et al. Early physical and occupa- 
tional therapy in mechanically ventilated, critically ill patients: a randomised controlled trial. Lancet 2009;373:1874-82.

15. Schaller SJ, Anstey M, Blobner M, Edrich T, Grabitz SD, Gradwohl-Matis I, et al. Early, goal-directed mobilisation in the surgical intensive care unit: a randomised controlled trial. Lancet 2016;388:1377-88.

16. London JA, Parry L, Galante J, Battistella F. Safety of early mobilization of patients with blunt solid organ injuries. Arch Surg 2008;143:972-6; discussion 977.

17. Clark DE, Lowman JD, Griffin RL, Matthews HM, Reiff DA. Effectiveness of an early mobilization protocol in a trauma and burns intensive care unit: a retrospective cohort study. Phys Ther 2013;93:186-96.

18. Engels PT, Beckett AN, Rubenfeld GD, Kreder H, Finkelstein
JA, da Costa L, et al. Physical rehabilitation of the critically ill trauma patient in the ICU. Crit Care Med 2013;41: 1790-801.

19. Patsaki I, Gerovasili V, Sidiras G, Karatzanos E, Mitsiou G, Papadopoulos E, et al. Effect of neuromuscular stimulation and individualized rehabilitation on muscle strength in intensive care unit survivors: a randomized trial. J Crit Care 2017;40:76-82.

20. Vorona S, Sabatini U, Al-Maqbali S, Bertoni M, Dres M, Bissett B, et al. Inspiratory muscle rehabilitation in critically Ill adults: a systematic review and meta-analysis. Ann Am Thorac Soc 2018 Mar 27 [Epub]. http://dx.doi.org/10.1513/ AnnalsATS.201712-961OC. 